\title{
DEVELOPMENT AND EVALUATION OF PNUMATIC PLANTER FOR SUGAR BEET PLANTING ON RIDGES \\ Salim, R. G. ${ }^{*}$ and H. M. Sarhan ** \\ *Agric. Eng. Res. Inst. Agric. Res Center. \\ ${ }^{*}$ Sugar crops. Inst., Agric. Res Center.
}

\begin{abstract}
This study was conducted on the developed Nibex planter, which originally designed mainly for planting on the flat ground, to be suitable for establishing the ridges while planting operation, by manufacturing beam, furrow opener replacing and fixed the manufactured ridge on the frame for establishing the ridge to the fabricated hoe wing which dragging the soil to the top of ridge that surrounding the sugar beet plant. The aim of this work is to develop and construct a ridge to be maximizing exploitation. The equipment was tested under different operating conditions, at wide of ridge $(0.60,0.70$ single row ridge and $1.0 \mathrm{~m}$ double - row ridge), depth of ridger $(0.10,0.15$, and $0.20 \mathrm{~m})$, distance between plants $(0.1,0.15,0.20$ and $0.25 \mathrm{~m})$ and tractor forward speed $(0.42,0.67,1.03$ and $1.36 \mathrm{~m} / \mathrm{s})$. The results showed that the optimum forward speed is $0.42 \mathrm{~m} / \mathrm{s}$, wide of ridge 0.60 one row, distance between plants $0.2 \mathrm{~m}$ and depth of ridger $0.20 \mathrm{~m}$ respectively where converted flat soil to ridge with high efficiency, maximizing the benefiting of the developed planter, decreasing the energy requirements by $46.5 \%$ by increasing forward speed from 0.42 to $1.36 \mathrm{~m} / \mathrm{s}$ and increasing root and sugar yield by 16.2 and $9.6 \%$ respectively about the recorded data for Nibex planter before modification.
\end{abstract}

\section{INTRODUCTION}

In Egypt most exporting planters of sugar beet planting on the flat ground needed more labors for hoeing and re-ridging to be establishing it to ridges. The Egyptian farmer was needy the ridge for suitable its irrigate system (shallow irrigate), improving drainage and give desired roots of sugar beet. Consequently, the production of sugar beet root and sucrose percentage increased. So this study aimed to developing Nibex planter for holding ridge directly while planting operation in order to offer the time, effort and cost.

Chaudhry (1985) mentioned that, water through furrows increased the above ground plant growth, root growth, grain yield and water use efficiency for most of crops.

Allam et al. 1988. Indicated that, sugar beet is considered as one of the most important crops not only for sugar production but also for producing fodder and organic matter for the soil. It extends to the use of its products in producing untraditional animal feed. Therefore government is planning to increase the growing area of sugar beet and improving the technique of agricultural processes. The prospective of mechanical growing of sugar beet in Egypt are very promising and can be adapted in the old valley farms and the newly reclaimed areas.

Raininko (1990) found that the best depth to planting mono-germ sugar beet coated seed is from 1 to $3 \mathrm{~cm}$. he also, indicated that the growth of sugar beet root go deep to $75 \mathrm{~cm}$. 
El-Zawahry (1994) showed that increasing planting forward speed of planter during planting sugar beet would decrease the depth of seeds in the soil, increase the seed scattering around the furrow center line and reduced machine efficiency and seed uniformity distribution.

Abdalla (1999) indicated that, the sowing process is considered one of the most agricultural operations. The art of planting seeds in the soil to obtain high germination ratio and healthy plants is the most important objective to achieve highest yield.

Abou Elmagd (2001) reported that environmental conditions are greatly influencing potato production quantity and quality. Among the environmental parameters, potato ridge dimensions, soil force reaction and soil moisture are the most influenced parameters. Hence he added that, the choice of planting machinery and systems is of great importance for developing potato planters.

Abd El-Tawwab, et al. (2007) developed a local fabricated sugar beet planter to form ridges during sowing operation to be control irrigation, improve drainage of excessive water, reduce the number of trips over the field, breakdown soil clods and create the optimum seed bed environment ready for seed germination. Thereby, these result in facilitate sugar beet seeding operation and to be maximize crop yield. Also, they added that, best results are found to be with some of its important parameters such as ridging depth $(7.5$ to $15 \mathrm{~cm})$, penetration angle $\left(20^{\circ}\right)$, wing setting angle $\left(40^{\circ}\right)$ and forward speed $(3.63 \mathrm{~km} / \mathrm{h})$.

\section{MATERIALS AND METHODS}

The experimental field work executed at the farms of Kafr El-Hamam Research Station- Sharkea Governorate-Egypt during sugar beet crop planting time in the two growing seasons of 2006 / 2007 and 2007/2008.

\section{Materials:}

\section{The utilized planter machine:}

The numerous pneumatic Nibex planters existent in sugar crops Research institute (Belkas branch), within the French project. They are planting on flat soil, that not suitable Egyptian condition and requirement to develop. Nibex planter has a four units made in Sweden consists of group of parts attached with frame bar hitching by three points with hydraulic system. It is provided with a steel plate having number of grooves distributed on the edge for feeding and metering of the seeds. The plate groove varies with seed type and its variety. Each plate type has a special number, which must be stated at ordering, several plate types can be used for the same seed for different seeding quantities. The choice of cell, seed level and seeding rate depends on the seed size. The planting depth is adjusted by changing the position of the ground wheel. As shown in fig. 3.1. Pneumatic planter (Nibex) has the following salient features:

1- Inter seed distance in each row can be adjusted from $10-25 \mathrm{~cm}$.

2- Inter row distance can be adjusted from $45-100 \mathrm{~cm}$ easily.

3- Depth of sowing can be adjusted to provide proper moisturizer to seed. 
4- Markers on both sides of Planter are helpful for straight line sowing and prevent multiple dropping of seeds.

5- Pneumatic seeding mechanism is operated by PTO of the Tractor and the Plate, which drops the seeds in soil in equal quantity and regular spacing.

6- Pneumatic system prevents the seeds from any breakage thus ensuring $100 \%$ utilization.

Specifications of developed planter:

\begin{tabular}{|l|c|}
\hline Description & Model: AG-46S \\
\hline Tractor HP Required & $45-85 \mathrm{Hp}$ \\
\hline Length, mm & 2000 \\
\hline Width, mm & 2570 \\
\hline Height, mm & 1200 \\
\hline Weight, Kg & 580 \\
\hline Seed Capacity, lit & 480 \\
\hline No. of rows & 4 \\
\hline Inter Row Distance & $450-880 \mathrm{~mm}$ \\
\hline
\end{tabular}

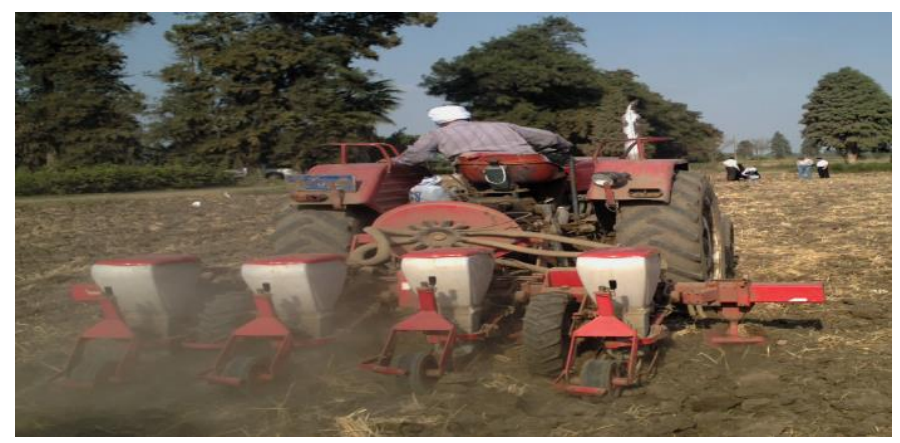

Fig. (1) Modified pneumatic Nibex planter while working in the field.

Fig. (2) Elevation for modified planter at different wide of ridges . 
Salim R. G. and Sarhan H. M.

Fig. (3) Plan, side views and different angles of added ridger.

Theoretical considerations:

Fig. (4): Schematic diagram for theoretical of one ridge crosses sectional area

From the above schematic diagram for theoretical ridge crosses sectional area can be calculated and predicted the area of formed ridge as below:

$\mathrm{S}_{1}=\mathrm{S}_{2}$

$\frac{\left(A+\frac{E-D}{2}\right) x d}{2}=\frac{\left(B+\frac{C}{2}\right) x h}{2}------(1)$

In the two homomorphous triangles $x y z$ and vyw can be resulting the following:

$\frac{x z}{v w}=\frac{d}{H}=\frac{x y}{v y}------------------------(2)$

$\therefore x y=\frac{d}{H} \times v y--------------------------(3)$

$\because v y=\frac{D-C}{2}---------------------------(4)$

5086 


$$
\begin{aligned}
& x y=\frac{D-C}{2} \times \frac{d}{H}------ \\
& \because B=\frac{D}{2}-x y---------- \\
& \therefore B=\frac{D}{2}-\frac{D-C}{2} x \frac{d}{H}------ \\
& A=\frac{E}{2}-B=\frac{E}{2}-\frac{D}{2}+\frac{D-C}{2} x \frac{d}{H}
\end{aligned}
$$

Substituting in Eq. (1) from Eqs. (2) and (3) values:

$$
\begin{aligned}
& \frac{\left(\frac{E}{2}-\frac{D}{2}+\frac{D-C}{2} x \frac{d}{H}+\frac{E-D}{2}\right) x d}{2}=\frac{\left(\frac{D}{2}-\frac{D-C}{2} x \frac{d}{H}+\frac{C}{2}\right) x H-d}{2}----- \\
& \frac{\left(\frac{E-D}{2} x d+\frac{D-C}{2} x \frac{d^{2}}{H}+\frac{E-D}{2} x d\right)}{2}=\frac{\left(\frac{D+C}{2} H-\frac{D-C}{2} x d-\frac{D+C}{2} x d+\frac{D-C}{2} x \frac{d^{2}}{H}\right)}{2}---(10) \\
& (E-D) x d=\frac{D+C}{2} x H-D d-----------------------(11) \\
& E d=\frac{D+C}{2} x H----------------------------(12) \\
& d=\frac{D+C}{2 E} x H------------------------(13) \\
& H=\frac{2 E d}{D+C}--------------------------(14) \\
& E=\frac{D+C}{2 d} x H-------------------------(15) \\
& h=\frac{2 E d}{D+C}-d-------------------------(16) \\
& D=\frac{2 E d-C H}{H}------------------------(17) \\
& C=\frac{2 E d-D H}{H}------------------(18)
\end{aligned}
$$

\section{Field experiments}

There are unchangeable factors; the ridger penetration angle $\left(20^{\circ}\right)$, the wing setting angle was ranged to be 35 to $50^{\circ}$ to the direction of travel. The average percentage of moisture content was found to be 13.76 to 15.21 $\%$. Multi-germ beet seeds were used in the present study. While the following changeable parameters:

1- Wide of ridge $(0.60,0.70$ single row ridge and $1.0 \mathrm{~m}$ double-row ridge named $E_{1}, E_{2}$ and $E_{3}$, resp.

2- Tractor forward speeds were adjusted to achieve four levels $(0.42,0.67$, 1.03 and $1.36 \mathrm{~m} / \mathrm{s}$ ) respectively, named $F_{1}, F_{2}, F_{3}$ and $F_{4}$.

3- Depth of ridger adjusted to attain three levels $(0.10,0.15$, and $0.20 \mathrm{~m})$ resp. named $d_{1}, d_{2}$ and $d_{3}$.

4- distance between plants $(0.1,0.15,0.20$ and $0.25 \mathrm{~m})$ respectively, named $d s_{1}, d s_{2}, d s_{3}$ and $d s_{4}$. 


\section{Experimental measurements:}

To study influence of the experimental treatments on the theoretical and actual weight of soil per one plant, lateral ridge profile, yield component, yield and quality of sugar beet and power requirement. Theses measurements were carried out three times after each test and the mean values were estimated. These measurements were as follows:

1. Theoretical and actual weight of soil per one plant:

Where:

The weight of soil per one plant $(\mathrm{kg})=\frac{D+C}{2} \times H \times D s \times A d---------(19)$

$\mathrm{D}=$ large base of trapezium.

$\mathrm{C}=$ small base of trapezium

$\mathrm{H}=$ high of trapezium.

Ds $=$ distance between plants

$\mathrm{Ad}=$ apparent density of soil $=1.5 \mathrm{~g} / \mathrm{cm}^{3}$.

2. Ridges cross sectional area and profile:

The operated soil profile was measured directly after every test with a profile meter of $100 \mathrm{~cm}$ length and distance between each two points $5 \mathrm{~cm}$ as shown in fig. (4). It was adjusted perpendicular to the planting direction after ridge operation. This device consists of one bar with numerous metallic sticks (thirteen) for height measurements.

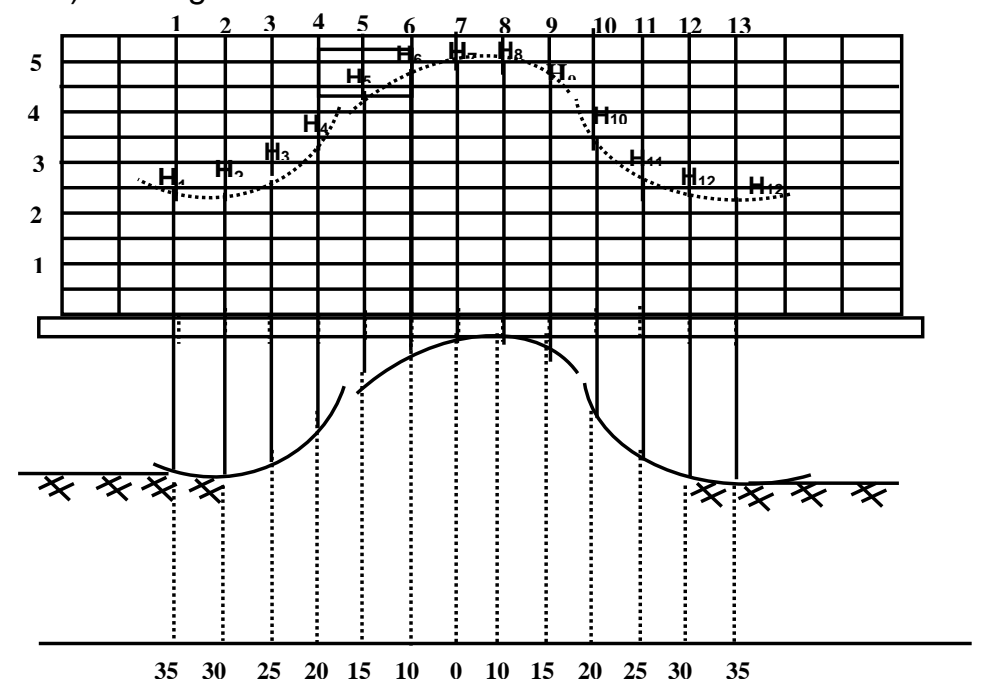

Fig. (5) Apparatus used for determining profile of ridged furrow cross section.

\section{Root yield:}

The average values of root yield were calculated after harvesting, ten plants were taken randomly from two inner ridges of each plot to estimate; root length, root diameter and root fresh weight ( $\mathrm{g} / \mathrm{plant}$ ), then calculated the root yield by following equation: 


$$
Y=\frac{42 \times M}{A}, M g / \text { fed. }---------------------(20) .
$$

Where:

$\mathrm{Y}=$ root yield, $\mathrm{Mg} / \mathrm{fed}$

$M=$ mass of lifted root, $\mathrm{kg}$.

$\mathrm{A}=$ harvested area, $\mathrm{m}^{2}$.

\section{Sugar yield:}

Sugar yield calculated by multiplying root yield by sucrose percentage (\%) that estimated polar metrically on lead acetate extract of fresh macerated roots according to the methods of Le-Docte (1927). This analysis conducted by the staff of laboratory of Belkas Sugar Factory, Dakhlia Sugar Company.

\section{Determination of fuel consumption:}

Fuel consumption per unit time is determined by measuring the volume of consumed fuel during harvesting time as follows: Before the test the fuel tank refilled completely and after the test measured the consumed fuel, the difference between the two volumes is the fuel consumed.

5. Power required $=3.163$ * fuel cons. (L/h). kW) ( Empapy 1985)

\section{RESULTS AND DISCUSSION}

\section{1- Effect of different tested factors on weight of soil per one plant:}

Data plotted graphically in Fig. (6) Show the effect of distance between plant, wide of ridge and depth of ridger on the weight of soil per one plant. It is obvious that increasing distance between plant, wide of ridge and depth of ridger tends to increase the weight of soil per one plant. Such as, for the same conditions of tractor forward speed $(0.42 \mathrm{~m} / \mathrm{s})$ and wide of ridge 0.6 $\mathrm{m}$ one ridge side 0.4 , increasing distance between plants from 0.10 to $0.25 \mathrm{~m}$ and increasing ridge depth from 0.10 to $0.20 \mathrm{~m}$ increased the weight of soil per one plant from 8.76 to $44.59 \mathrm{~kg} / \mathrm{plant}$. This result means that, the optimum wide of ridge for increasing weight of soil per one plant was the highest one $(1 \mathrm{~m})$. This behavior is owing to action of high depth of ridger and wide of ridge led to increasing weight of soil. The weight of soil per one plant had an directly relationship with the wide of ridge and depth of ridger and had indirect effect with tractor forward speed, this may be due to increasing forward speed led to preventing machine soil implements to no more penetrated in soil, and not encourage more soil accumulate to constructed big ridge. From actual data, it noticed that, at depth of ridger of $(0.2 \mathrm{~m})$, distance between plants $(0.25 \mathrm{~m})$ and wide of ridge $(0.60,0.70$ and $1.0 \mathrm{~m})$, the weight of soil per one plant $(44.59,51.2$ and $74.57 \mathrm{~kg} / \mathrm{plant})$ respectively. But recommended $44.59 \mathrm{~kg} / \mathrm{plant}$ that achieving at wide of ridge $(0.60 \mathrm{~m})$, depth of ridger $(0.20 \mathrm{~m})$, distance between plants $(0.25 \mathrm{~m})$ and tractor forward speed $(0.42 \mathrm{~m} / \mathrm{s})$ and give the highest altitude of ridge $(0.21 \mathrm{~m})$ that improving the environment of sugar beet root growth for better response to minimum irrigational water and for facilitating excessive drainage. Consequently the production of sugar beet root and the sucrose percentage could be increased; this result comes with Abd El-Tawwab et al. (2007). 

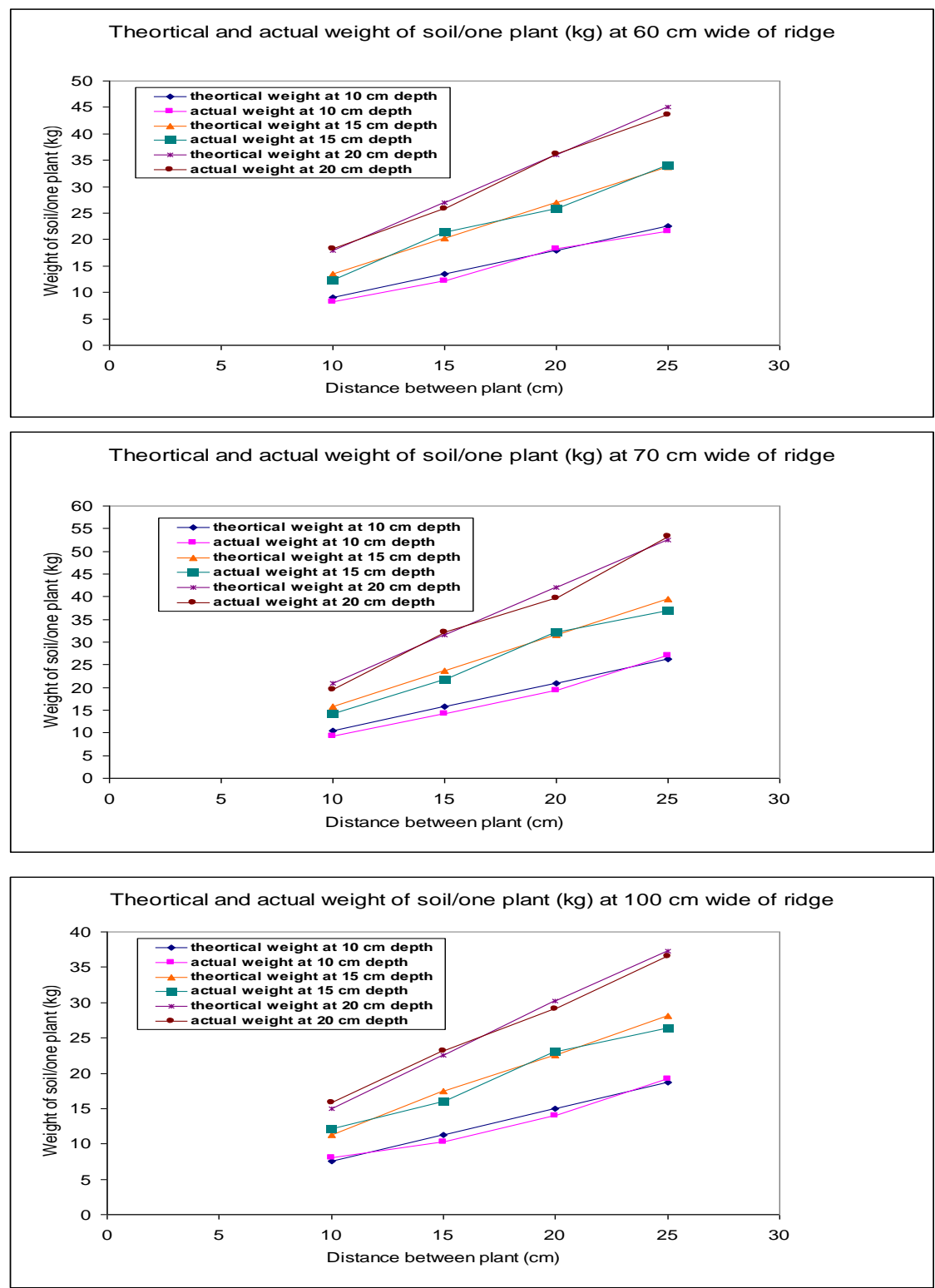

Fig. (6) Weight of soil /one plant at studying factors at tractor forward speed $0.42 \mathrm{~m} / \mathrm{s}$. 

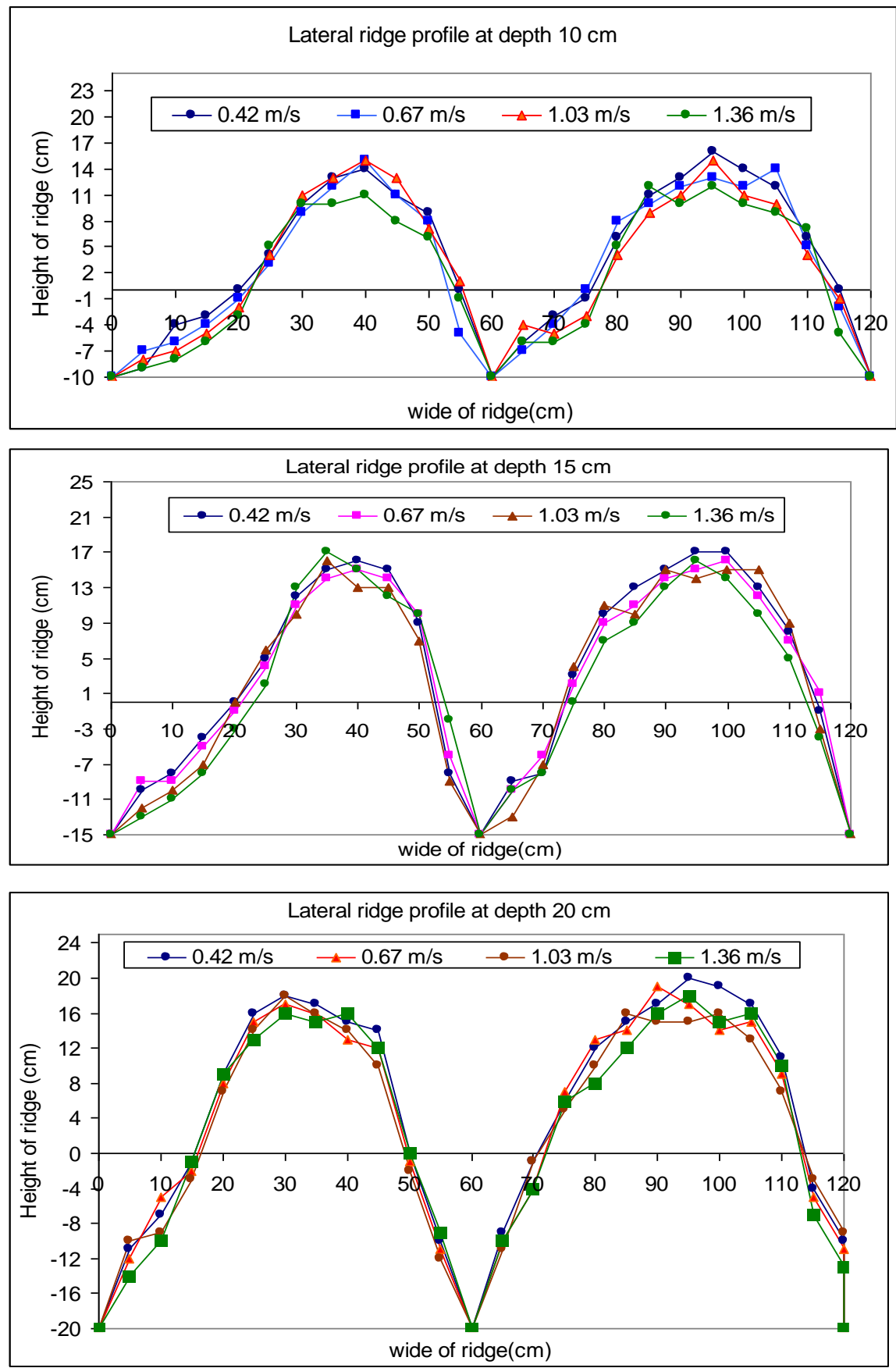

Fig. (7) Lateral ridge profile at tractor forward speed $0.42 \mathrm{~m} / \mathrm{s}$ and wide of ridge $60 \mathrm{~cm}$. 
Salim R. G. and Sarhan H. M.
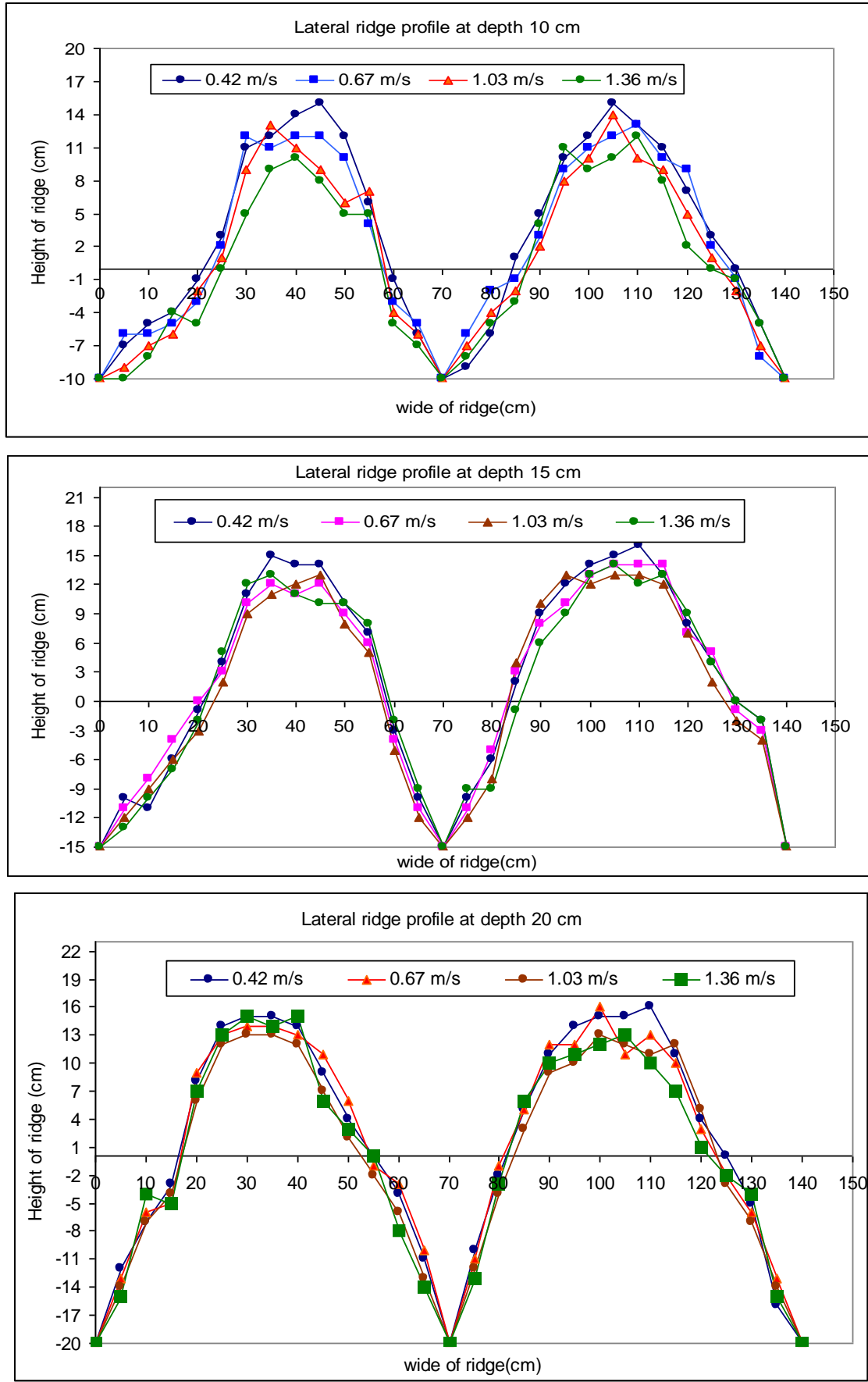

Fig. (8) Lateral ridge profile at tractor forward speed $0.42 \mathrm{~m} / \mathrm{s}$ and wide of ridge $70 \mathrm{~cm}$. 
J. Agric. Sci. Mansoura Univ., 33 (7), July, 2008
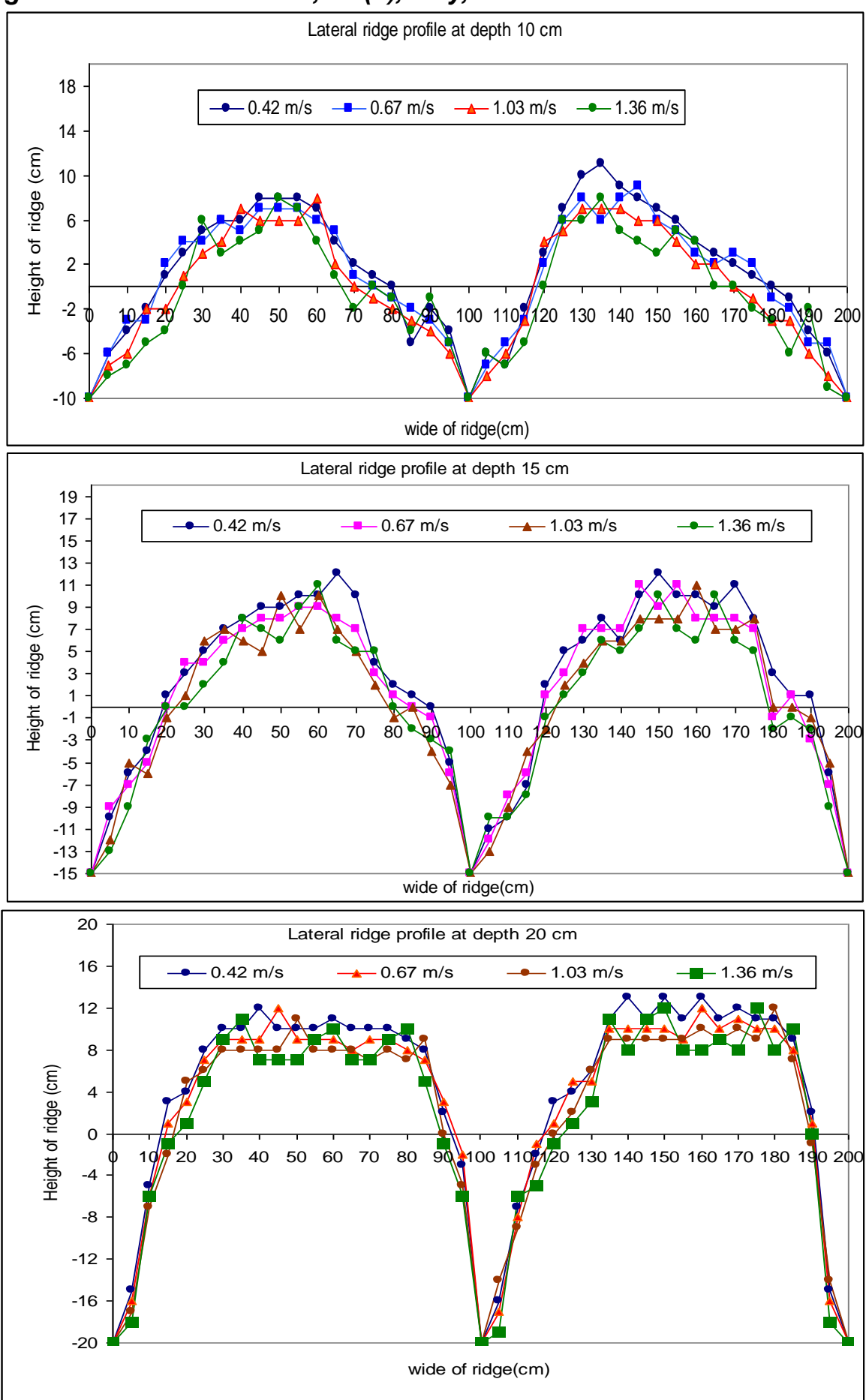

Fig. (9) Lateral ridge profile at tractor forward speed $0.42 \mathrm{~m} / \mathrm{s}$ and wide of ridge $100 \mathrm{~cm}$. 


\section{Effect of tested factors on root and sugar yield:}

Total root and sugar yield decrement linearly with increasing wide of ridge, and tractor forward speed, but they increment linearly with increasing depth of ridger and height of ridge, they increasing linearly with increasing length and diameter of root as shown Figs. (10 and 11), one can seen that, increasing wide of ridge from $0.60 \mathrm{~m}$ to $1.0 \mathrm{~m}$ at forward speed $(0.42 \mathrm{~m} / \mathrm{s})$, depth of ridger $(0.20 \mathrm{~m})$ and distance between plants $(0.25 \mathrm{~m})$ decreased the root and sugar yield from 26.31 to $24.35 \mathrm{mg} / \mathrm{fed}$. and from 7.01 to 6.34 respectively. This may be due to higher height of ridge rate by increasing the depth of ridger, that led to absorbing moisture content difficultly and, therefore rapidly increase the diffusion rate of oxygen that detriments to plant growth. Therefore higher yield achieved with the highest depth of ridger and distance between plants and lowest of wide of ridge is often linked to the deficiency - soil moisture content as well as to shortage - dry conditions during the early growth of sown beet crops which led to earlier emergence. So the forward speed $0.42 \mathrm{~m} / \mathrm{s}$, depth of ridger $0.2 \mathrm{~m}$, wide of ridge $0.6 \mathrm{~m}$ and distance between plants $0.25 \mathrm{~m}$ are recommended for increasing the total root and sugar yield.

\section{Effect of tested factors on energy requirement $(\mathrm{kW} . \mathrm{h} / \mathrm{mg})$ :}

Data presented in Table (1) shows the effect of forward speed, wide of ridge on the energy requirement which affected by mentioned tested factors. One can said that the increasing the forward speed from 0.42 to 1.36 $\mathrm{m} / \mathrm{s}$ decreased the energy requirement from 13.39 to $6.29 \mathrm{~kW} . \mathrm{h} / \mathrm{fed}$. (46.9\%) for wide of ridge $0.6 \mathrm{~m}$. This may be due to increasing the fuel consumption by increasing the forward speed which caused augmenting the productivity (fed./h). While increasing wide of ridge from 0.6 to $1 \mathrm{~m}$ decreased the energy requirement from 13.39 to $12.80 \mathrm{~kW} . \mathrm{h} / \mathrm{fed}$. (95.5\%) at forward speed 0.42 $\mathrm{m} / \mathrm{s}$. This may be due to increased wide of ridge led to decreasing the fuel consumption that led to decreased the energy requirement (kW.h/fed.).

Table (1) Effect tested factors on productivity, power requirement, (kW) and energy requirement (kW.h/fed.) for modified planter.

\begin{tabular}{|l|c|c|c|c|c|c|c|c|c|c|c|c|}
\hline $\begin{array}{l}\text { Wide } \\
\text { of } \\
\text { ridge } \\
\text { (m) }\end{array}$ & \multicolumn{10}{|c|}{ Productivity (fed./h) } & \multicolumn{9}{|c|}{$\begin{array}{c}\text { Power requirement } \\
\text { (kW) }\end{array}$} & \multicolumn{3}{|c|}{$\begin{array}{c}\text { Energy requirement } \\
\text { (kW.h/fed.) }\end{array}$} \\
\hline & $\mathrm{F}_{1}$ & $\mathrm{~F}_{2}$ & $\mathrm{~F}_{3}$ & $\mathrm{~F}_{4}$ & $\mathrm{~F}_{1}$ & $\mathrm{~F}_{2}$ & $\mathrm{~F}_{3}$ & $\mathrm{~F}_{4}$ & $\mathrm{~F}_{1}$ & $\mathrm{~F}_{2}$ & $\mathrm{~F}_{3}$ & $\mathrm{~F}_{4}$ \\
\hline 0.6 & 1.08 & 1.72 & 2.65 & 3.50 & 14.46 & 16.48 & 19.23 & 22.05 & 13.39 & 9.566 & 7.261 & 6.295 \\
\hline 0.7 & 1.26 & 1.78 & 2.74 & 3.61 & 16.06 & 17.09 & 19.87 & 23.97 & 12.74 & 9.598 & 7.261 & 6.633 \\
\hline 1 & 1.08 & 1.72 & 2.65 & 3.50 & 13.82 & 15.65 & 18.69 & 20.86 & 12.80 & 9.083 & 7.056 & 5.957 \\
\hline
\end{tabular}


J. Agric. Sci. Mansoura Univ., 33 (7), July, 2008
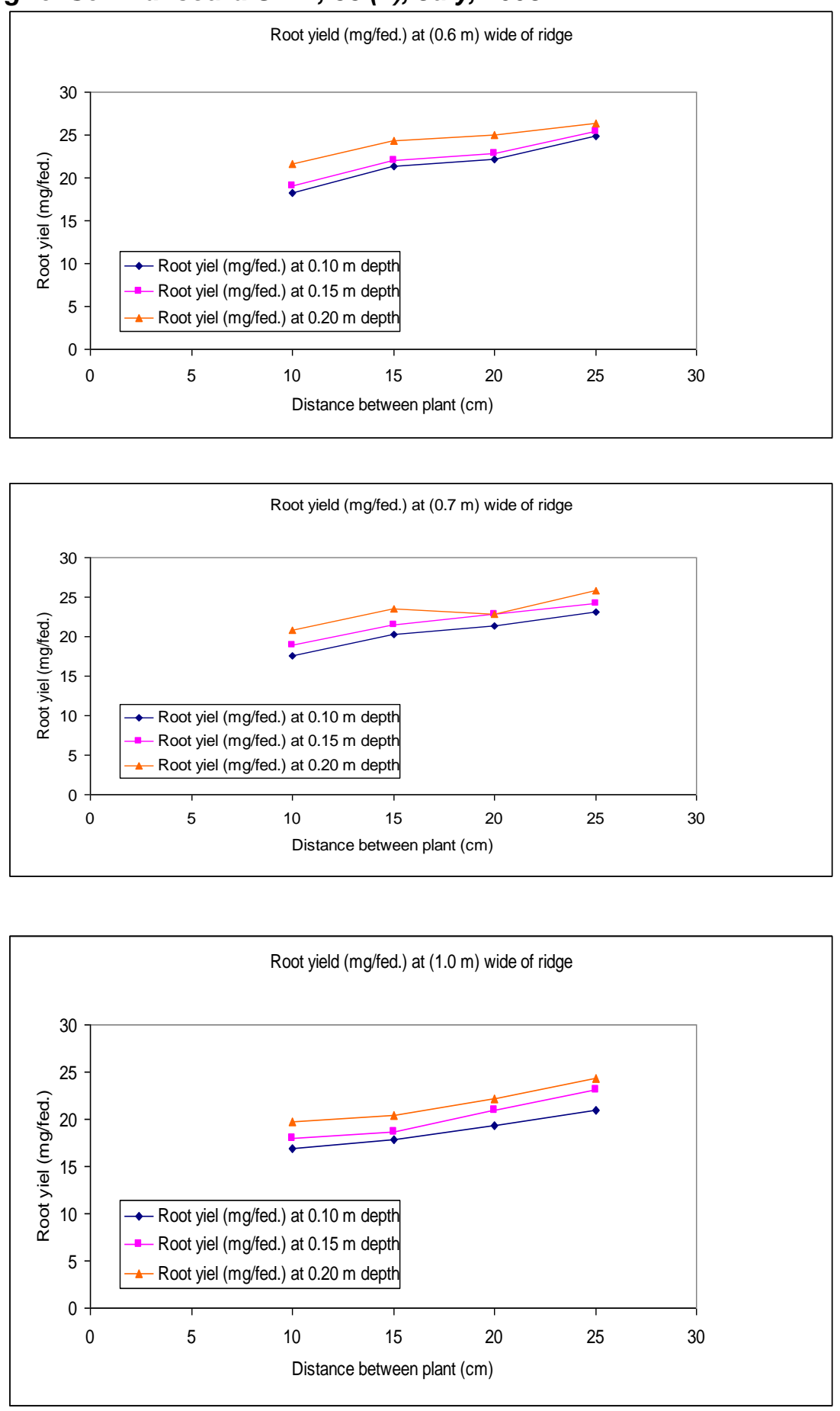

Fig.(10) Root yield (mg/fed.) at tractor forward speed $0.42 \mathrm{~m} / \mathrm{s}$. 
Salim R. G. and Sarhan H. M.
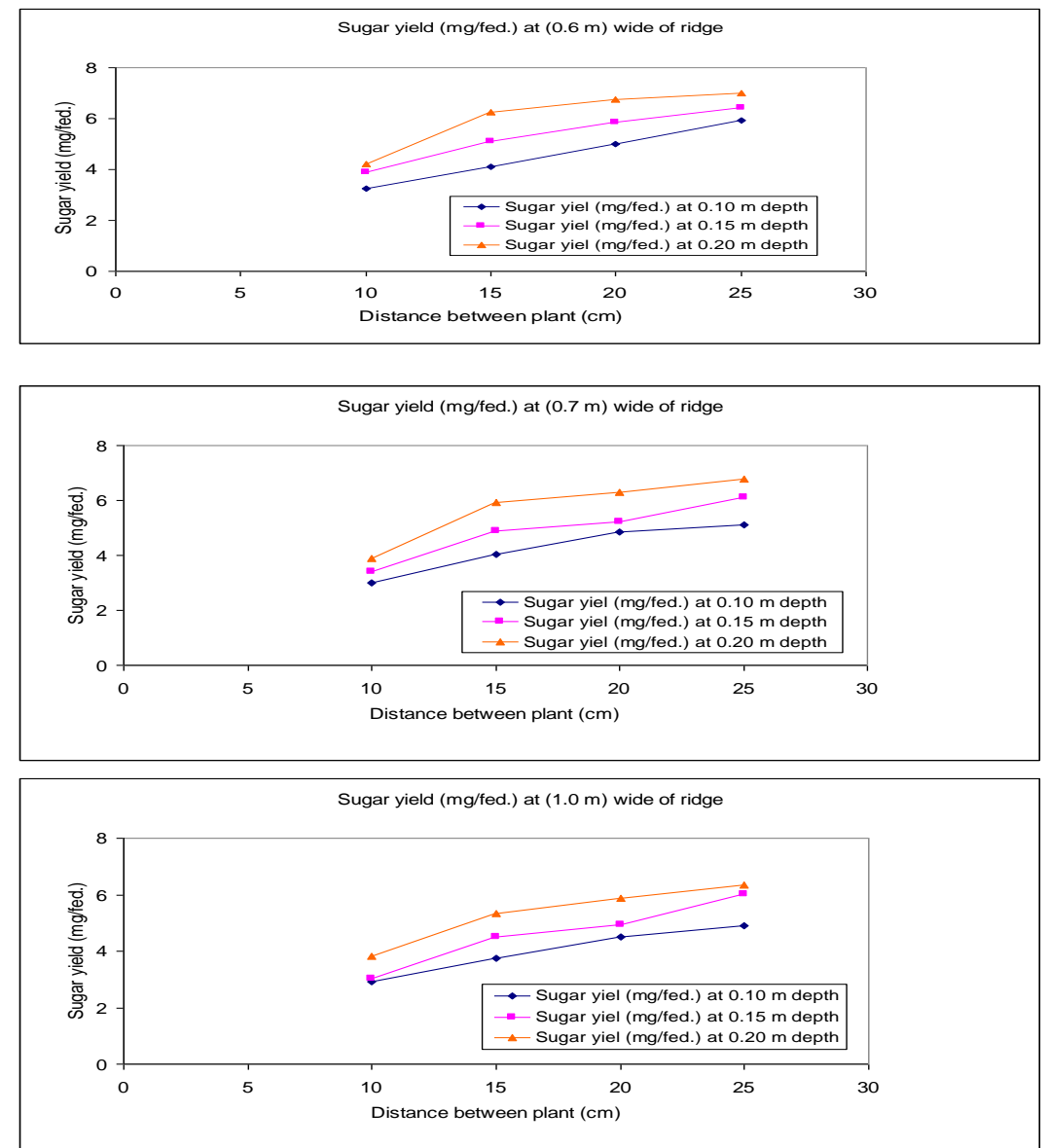

Fig.11 Sugar yield (mg/fed.) at tractor forward speed $0.42 \mathrm{~m} / \mathrm{s}$.

\section{Conclusion}

1. The results showed that farmers can be used the developed pneumatic Nibex planter machine for getting the high yield of root and sugar beet.

2. The optimum operating conditions of developed Nibex planter were found to be as follows:

Tractor forward speed was $1.52 \mathrm{~km} / \mathrm{h}(0.42 \mathrm{~m} / \mathrm{s})$, moisture content of soil about 13.76 to $15.21 \%$ on wet bases, penetration angle $\left(20^{\circ}\right)$, the wing setting angle was ranged to be 35 to $50^{\circ}$ to the direction of travel. Wide of ridge was $(0.60$ single row ridge, distance between plants $(0.25 \mathrm{~m})$ and depth of ridger $(0.20 \mathrm{~m})$, respectively. That constructed the optimum ridge and lowest time consumed, decreasing the energy requirements by $46.5 \%$ by increasing forward speed from 0.42 to $1.36 \mathrm{~m} / \mathrm{s}$ and increasing root and sugar yield by 16.2 and $9.6 \%$ respectively about the recorded data for Nibex planter before modification. The results of this article may recommend that using the new design the developed planter machine to be suiting small holdings that spreading in Egyptian countryside. 


\section{REFERENCES}

Abd El-Tawwab, I. M. (2007). "Developing and performance evaluation of a locally fabricated sugar beet planter" Misr J. Agric. Eng. 24 (4): pp. 648 $-665$.

Abdalla, H. El. (1999). "Performance evaluation of developed planter furrow opener" Misr J. Agric. Eng. 16 (2): pp. 176 -192.

Abou Elmagd, A. E.; (2001) "Potato tuber - soil cmutual stress under different machinery traetments" J. Agric. Sci. Mansoura Univ.26 (12): pp. $7953-7967$.

Allam, A. I.; A. H. Nour and M. A. Farag (1988) " "Perspectives of sugar beet mechanical growing" Agric. Res. Review., Ag. Res. Center, Giza, Egypt, 66 (3) pp. $537-543$.

Chaudhry, T. N. (1985) "Response of wheat to irrigation with small amount of water applied in various ways" Agriculture water Management.,82 (1): pp. $158-159$.

El-Zawahry, A. S. M. (1994) "A study on mechanization of some operation sugar-beet production" M. Sc. Th. Ag., El-Azhar Univ. Egypt, pp 18-19.

Embaby, A. T. (1985) "A comparison of different mechanization system for cereal crop production" M. Sc. Thesis, (Ag. Eng.,) Cairo Univ.

Le-Docte, A. (1927)" Committal determination of sugar in the beet rootusing the schar" Le-Docte process Inst. Sug. Jour 29; pp. 482-488.

Raininko, K. (1990) " Sweeden sugar beet p." J of sugar No 1, 29, 32 and 62.

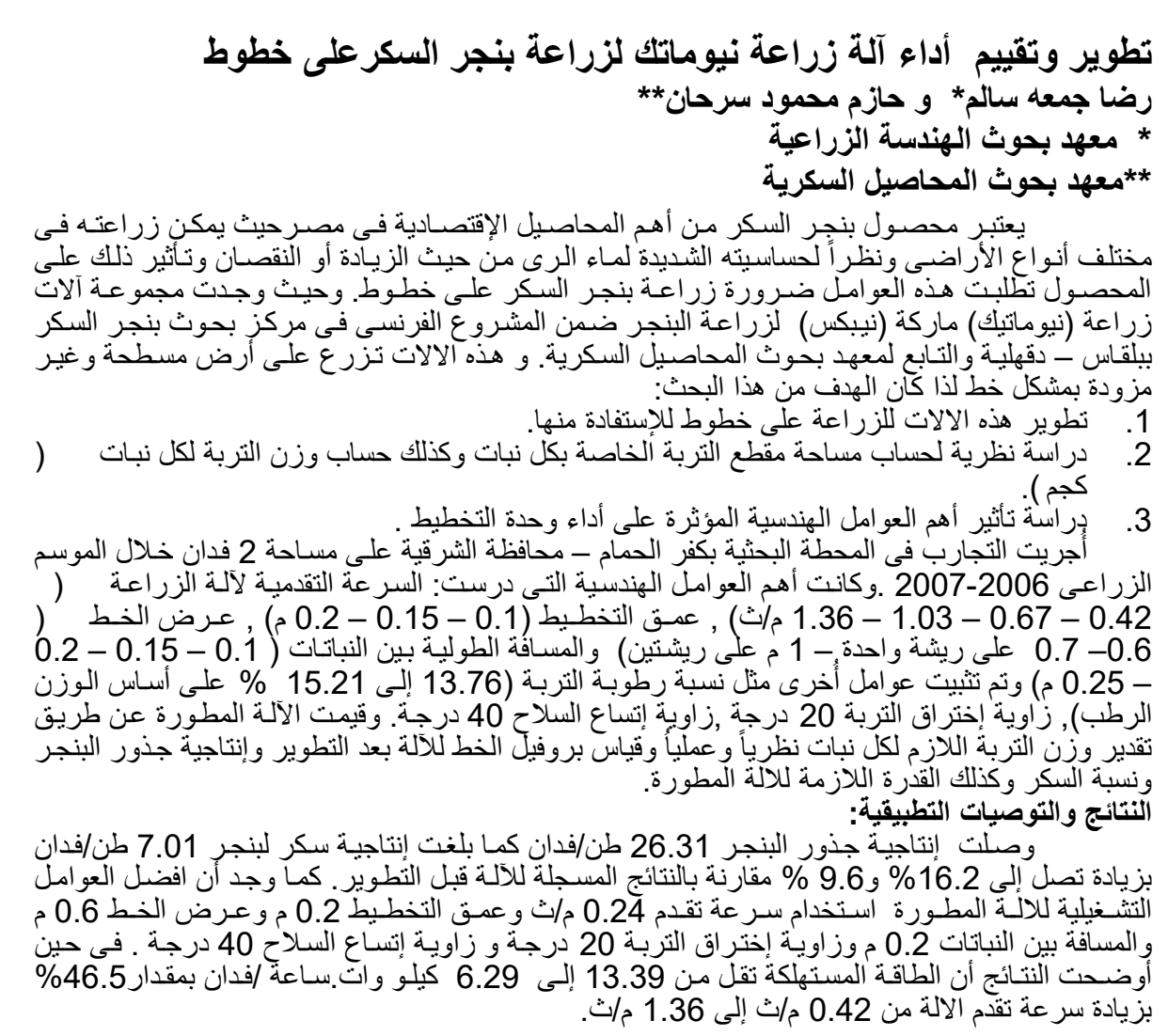


Salim R. G. and Sarhan H. M.

5098 